\title{
American Association of Geographers Annual Meeting
}

\author{
Logan Emlet \\ Seattle, WA (Virtual) \\ April 7-11, 2021
}

The Annual Meeting of the American Association of Geographers (AAG) took place virtually on April 7-11, 2021. The association intended to hold the five-day conference in Seattle, WA, but the ongoing COVID-19 pandemic required proceedings to move online. Virtual format notwithstanding, more than 5,100 geographers, environmental scientists, and other attendees convened for five days of programming that included approximately 3,000 presentations, workshops, and field trips.

This year's conference featured a number of keynote speakers, plenary sessions, and award ceremonies, as well as the requisite business meetings. Themes were: Geographers and COVID-19: Setting Our Direction for the Future; Geographies of Access: Inclusion and Pathways; Ethnonationalism and Exclusion around the World; The Changing North American Continent; and Expanding the Community of Geography. Nearly 1,000 sessions explored these and other topics, while diverse symposia brought together contributions on Geospatial Health, Human Dynamics Research, Dendrochronology, and Human Dimensions of Global Change (Hazards, Risks, and Disasters). In another conference highlight, AAG Vice President Emily Yeh (University of Colorado Boulder) interviewed Naomi Klein (Rutgers University) about climate related research in geography, youth and academic activism, and environmental justice more broadly.

This year's AAG conference hosted at least three sessions with a specific focus on Himalayan research, and at least twenty-three other sessions featured presentations on Nepal and Himalayan geographies.

On Friday, the 8th Annual Nepal and Himalayan Geographies Roundtable panel, organized by Galen Murton (James Madison University) and Rupak Shrestha (University of Colorado Boulder), convened for an hour and a half of warm conversation focused on building community amongst geographers of the Himalaya. After introductions, the discussion turned to pandemic-related opportunities and challenges for research, ways to support younger scholars, questions concerning collaborative research and co-authorship, and possibilities for further institutionalization of Himalayan geographies within and beyond AAG. Virtual format notwithstanding, nearly thirty people attended, and the roundtable remains a wonderful venue for community, collaboration, and conceptualizing future directions for Nepal and Himalayan geographies.

On Saturday, Parveen Chhetri (California State University Dominguez Hills) and Jeremy Johnson (Prescott College) organized a panel on vegetation dynamics in the Nepal Himalaya. Narayan Gaire (Tribhuvan University) introduced treeline research, commented on the history of the field in Nepal, and suggested potential directions for future studies. Michelle Mohr (California State University Dominguez Hills) examined the effects of climate change on successional dynamics in mixed fir-birch stands in Dhorpatan, and Prakash Aryal (Tribhuvan University) suggested that endemic Larix species may be a good candidate for past climate reconstruction on the basis of temperature, rainfall, and drought indices found in tree-ring samples. Finally, Parveen Chettri addressed the impacts of climate change on forest ecosystems in upper transition treeline ecotones by way of a dendroecological study of three species across three regions of the Nepal Himalaya.

On Sunday, Mabel Gergan (Vanderbilt University) and Pavithra Vasudevan (University of TexasAustin) organized an Author Meets Critics panel for Sara Smith's, Intimate Geopolitics: Love, Territory, and the Future on India's Northern Threshold (2020), which takes up the entanglement of affective, embodied intimacies and geopolitics in contemporary Ladakh. Emily Yeh, Ather Zia (University of Northern Colorado), Rupak Shrestha, Jennifer Fluri (University of Colorado Boulder), and Dalia Bhattacharjee (University of North Carolina) gave insightful commentary and 
asked productive questions of this important new book.

In addition to the above sessions focused squarely on Nepali and Himalayan contexts, a wide range of other presentations concerning Nepal and the Himalayas included the following:

\section{COVID-19}

Numerous panels collated research on the novel coronavirus from diverse methodological and theoretical perspectives. Two sessions featured presentations on COVID-19 and the Himalaya. In a panel organized by Harry Fisher (Swedish University of Agricultural Sciences), Divya Gupta (Indian School of Business) presented on the effects of the pandemic on rural livelihoods in Himalayan India and Nepal; Falak Jalali (University of Iowa) explored how COVID19's disruption of schooling in Himachal Pradesh affects educational plans and aspirations; Dil Khatri (Southasia Institute of Advanced Studies) discussed the implications of government decentralization on coronavirus response in Nepal, and Harry Fisher suggested, on the basis of research in Himachal Pradesh, that the institutional capacity to respond to COVID-19 and associated socioeconomic shocks must be understood in terms of specific histories of investment in robust subnational systems of governance. In another panel, Mountain Sentinels Fellows reported on their research: Phurwa Dhondup (University of Colorado Boulder) spoke to his ongoing study of local etiologies and histories of epidemic disease in Dolpo, while Bidhya Sharma (McGill University) reported on the socioeconomic effects of last year's pandemicinduced cancellation of Dolpo's caterpillar fungus harvest season.

\section{Time, Politics, and Social Change}

A number of talks at the conference asked probing questions about the politics of time, aspiration, belonging, and knowledge production. of particular note, a day-long series of panels co-organized in part by Mabel Gergan (Vanderbilt University) and Sara Smith (University of North Carolina) entitled Desirable Futures: Time as Possibility, Practice, Politics, facilitated diverse reflections from participants who problematized modernist and colonialist constructions of time by drawing attention to other ways of being, living, and worldmaking. As part of this series, Mabel Gergan drew from research in Ladakh and Sikkim to reveal ways that young people negotiate the Indian state's system of tribal reservation and its territorial and temporal frameworks in order to conceptualize and enact unique tribal futurities; Anisa Bhutia (Tata Institute of Social Sciences) reflected on what it means for a place, in this case Kalimpong, to die and consequently what it meant/ means for it to live; and Dolly Kikon (University of Melbourne) explored how fraught forms of sociality and concepts like modernity and citizenship congeal around the material communities, human and microbial, that produce fragrant fermented ahkuni in Northeast India. In other panels, Ahmar Alvi (Aligarh Muslim University) addressed the politics of food in Northeast India in a presentation on the Slow Food Youth Network of Nagaland; Mai Kobayashi (Research Institute for Humanity an Nature, Japan) looked at how competing myths of modernity influence Bhutan's promotion of organic agriculture; Shangrila Joshi (The Evergreen State College) argued that Newa Guthi should be understood as an indigenous institution for climate resilience; and through an analysis of three cookstove types from the Indian Himalaya, Deepti Chatti (Humboldt State University) asked what a feminist approach to developing energy technology would look like. Finally, Shamayeta Bhattacharya (University of Connecticut) discussed non-binary gender and trans identities, experiences, and politics in comparative perspective across South Asia, including Nepal.

\section{Infrastructure and Geopolitics}

Infrastructure and geopolitics intersected in several panels at this year's conference, featuring talks about the Himalaya. Galen Murton contrasted the spectacular promotion of Belt and Road Initiative (BRI) infrastructure projects in Nepal and Tibet with the conspicuous representational absence of these same projects in BRI maps. Robert Farnan (University of York) explored dynamics of organizational (in)formality, planning, and knowledge infrastructures in risky and urbanizing spaces through a comparison of Nepali and Thai cases. And Nadine Plachta (University of Toronto) addressed shifting valuations of, and possibilities for, authority/dissent, success/failure, and investment/divestment in NepalTibet borderlands by centering on the economic geographies of traders and businesspeople.

\section{Space, Scale, Resources}

Three talks took up spatial analyses of resource management and development in Nepal. Padmendra Shrestha (University of Arizona) examined the negotiation of project boundaries which determine the uneven distribution of costs and benefits associated with hydropower development. Shreejana Bhattarai (University of Florida) used geospatial software to map recent spatiotemporal patterns in Nepal's malaria 
eradication programs. And Kripa Thapa (University of Utah) modeled supply and demand of hydrological systems in Nepal at a sub-basin level to assess vulnerabilities associated with projected glacial melt.

\section{Hazards: Social and Spatial Assessments and Analysis}

A series of panels focused on multiple facets of hazards, risks, and disasters research, featuring a number of talks on the Himalaya. Rajiv Ghimire (Arizona State University) evaluated the implementation and efficacy of initiatives in Nepal that integrate local knowledge and bottom-up planning in development and climate change adaptation programs; Asmita Bhattarai (University of Utah) proposed a seismic risk and postearthquake damage assessment framework for Nepal; Sudikshya Bhandari (University of California Davis) examined socio-cultural, environmental, and economic challenges to reconstruction of vernacular architecture in postearthquake rural Gorkha; and Janardan Mainali (Stetson University) used a data-driven spatial patters analysis to analyze hazard risks and vulnerabilities of marginalized communities in Nepal. Furthermore, Saeed Akhtar Khan (University of Bayreuth, Germany) mapped past disasters in the eastern Hindu Kush, namely floods and landslides, to better understand the ways they have shaped and been shaped by human land-use and vegetation dynamics, and David Porinchu (University of Georgia) presented a poster on research using lakebed core samples to identify abrupt hydroclimatic change in the Garhwal Himalaya.

\section{Community Forestry}

Continuing a rich tradition, this year's conference included several presentations on community forestry in Nepal. Conghe Song (University of North Carolina) organized a panel on forest policy and forest-dependent livelihoods in which Prabisha Shrestha (University of North Carolina) spoke to the influence of socioeconomic heterogeneity on fuelwood usage in and around community forests, and Rajesh Bista (University of North Carolina) explored multiple factors, including community forestry regulations, that may contribute to cropland abandonment in Nepal. Alexander Smith (Oregon State University) evaluated the long-term impacts of community forest management on forest conditions in a study incorporating Landsat imagery and open-ended interviews with forest users, and Zoya Husain (Imperial College London) applied the Diffusion of Innovation theory to Nepal to better understand key drivers and challenges to the adoption of community forestry.

Beyond paper sessions, conference attendees had numerous opportunities to network, build institutional capacity, and to see
Seattle's sights on virtual tours of the Pioneer Square and Capitol Hill districts. And in addition to workshops and training sessions, participants could partake in virtual coffee and happy hours and compete in the annual World Geography Bowl.

The 2021 Annual Meeting of the American Association of Geographers was as much an actual as a virtual success. Geographers of Nepal and the Himalaya contributed unique perspectives on issues of world historical importance, enriching theoretical and applied research through community praxis. The conference itself was both an opportunity for learning and a model for future online conferencing, as academics come to terms with the carbon footprint of conference travel. And AAG remains a forum in which to organize collaborative research. Next year's AAG Meeting is scheduled for 25 February - 1 March, 2022 in New York City and will provide many more exciting opportunities to engage students of Nepal and the Himalaya, as well as geographers more generally, in discussions about spatial, social, and environmental worlds, their pasts, and potential futures.

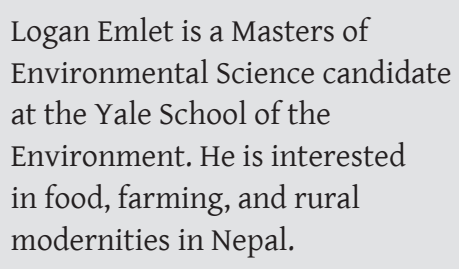

